\title{
Responding to Change: Reinventing Librarian Identities in the Age of
}

\author{
Research Mandates
}

Running Head: Reinventing Librarian Identities in the Age of Research Mandates

Citation: Ann Glusker, Nina Exner. (2018). "Responding to Change:

Reinventing Librarian Identities in the Age of Research Mandates", in

George J. Fowler, Samantha Schmehl Hines (ed.) Challenging the "Jacks of

All Trades but Masters of None" Librarian Syndrome (Advances in Library Administration and Organization, Volume 39) Emerald Publishing Limited, pp.91 - 115 .

URL: https://www.emeraldinsight.com/doi/abs/10.1108/

S0732-067120180000039007

ISBN: 978-1-78756-904-1 eISBN: 978-1-78756-903-4 


\begin{abstract}
This chapter outlines libraries’ (and librarians') changing identities in the new world of research mandates from funders, institutions, and publishers. As libraries respond to the demands of these mandates on their users at the individual, departmental and institutional levels, they need to revise their approaches to relationship building and user engagement, as well as maintain flexibility in the face of changing roles and skill requirements. This chapter will (1) outline the changing scholarly ecosystem; (2) summarize major terms and concepts to understand the process of producing research outputs; (3) discuss the perspectives of the major players in the research enterprise; (4) present some of the challenges that research mandates and the changing research environment have brought to libraries; and finally (5) review ways in which libraries have successfully addressed them. The focus here is on the academic research setting, although many of the strategies outlined can be equally applicable in both non-academic research and nonresearch funding contexts.
\end{abstract}

\title{
Keywords:
}

Funder research mandates

Institutional research mandates

Open access publishing

Data sharing

Research data management

Scholarly communication 


\section{Introduction}

Since the advent of the internet, libraries have undergone a sea change. At every point of change in the last thirty years or so, libraries have faced choices of momentous consequence, as they decided whether and how to hold onto or shift their identities regarding collections, services, programming and outreach, and more.

The challenges have arguably been greatest in academic institutions, where libraries’ longstanding involvement in the scholarly communications cycle has placed them in the midst of fast-moving and high-stakes changes in the world of research, research funding, publishing, and, more recently, data management. Libraries must be constantly aware of their mission, their institution's mission, the needs of their constituents, and their own capacity as they navigate these challenges. However, libraries also bring unique offerings to the changing academic landscape. The very diversity of skills in libraries position them to be particularly valuable to colleges and universities navigating the evolving academic research landscape.

In this chapter, we will discuss libraries' (and librarians') changing identities in the new world of research mandates from funders, institutions, and publishers. As libraries respond to the demands of these mandates on their users at the individual, departmental and institutional levels, they need to re-shape their approach to relationship building and user engagement, as well as maintain flexibility in the face of changing roles and skill requirements. We will (1) outline the changing scholarly ecosystem; (2) summarize major terms and concepts to understand about the process of producing research outputs; (3) discuss the perspectives of the major players in the 
research enterprise; (4) present some of the challenges that research mandates and the changing research environment have brought to libraries; and finally (5) review ways in which libraries have successfully addressed them. This discussion will focus on the United States context, although many of the same trends are occurring internationally, and the literature is particularly rich from the United Kingdom. We will also, as mentioned, focus on the academic research setting, although many of the strategies outlined can be equally applicable in both non-academic research and non-research funding contexts.

\section{Changes in the Scholarly Ecosystem}

Academic libraries have long been essential to the research enterprise, as recognized in the earliest guidelines of government funding for institutions receiving research grants (Zbylut, 1992). For many disciplines, library support has traditionally focused on collections, particularly the essential function of managing monographic and serial collections. Although changes in government funding for research recognized the multifaceted support from libraries (Zbylut, 1992), much of the emphasis of the role of the library in research support has focused on the collection (United States Office of Management and Budget, 2004). This reflects the historical and ongoing importance of the collection to researchers.

However, the move to e-resources and availability of content from researchers' desktops has diminished awareness of the library’s role as a source of intellectual content. Researchers often 
do not realize that the content they so easily access has been purchased and provided (often after labor-intensive and complex negotiations) by their institution’s library. As a result, organizational recognition and support of libraries becomes harder to sustain, putting additional pressure on librarians in their outreach efforts. One major response has been the broadening of roles for liaison librarians (generally specialist outreach librarians, usually assigned to build relationships with a specific academic unit) who may seek new and different ways of engaging with their users. One example is their seeking to become more embedded in their departments, thereby spending significant time as “insiders” in the assigned department’s space, meetings, and/or classes.

The move to online collection formats is only one small aspect of the larger changes over the past three decades that have visited both the scholarly ecosystem (the broader research landscape: research funding, research careers, institutional investments in research, etc. (Jubb, 2012)) in general and scholarly communication (activities around sharing scholarly research: peer review, publishing, archiving, etc.) in particular. Scholarly communications have experienced both pressures and opportunities. On the one hand, budgets for journals have been squeezed between shrinking resources and ballooning journal prices; on the other, online information has enabled new opportunities to emerge based on growing information availability and vast potential for collaboration. An ethic of openness has developed as researchers find new opportunities based on digital sharing of protocols, data, and findings. Shifts in scholarly publishing models and the move toward open access have been two of the most important changes in the scholarly ecosystem. 
Researchers and especially university faculty must be able to have dissemination outlets for their work; to date the predominant outlet in the sciences and social sciences is the journal article. Each researcher's intellectual profile and accomplishments are contained in their record of publications, and these are used for acquiring tenure (permanent status) at institutions, and for enhancing professional reputations leading to further opportunities. Institutions support this system, as it is to their advantage to bolster the professional profiles of their researchers. In fact, as outlined by Mangiafico and Smith (2014), the system has developed to the point where institutions typically pay the entire cost of publication processes for their members, although many of those costs are hidden. Not only that, but the system has reached the point at which publishers have added enough value to the process (quality standards, access integration, discoverability tools) and hold enough of a monopoly over the production of journal outputs that they both can insist that authors give up rights to their published work and also charge high prices for the finished product. The university supports the work, the researchers create it, and then the university must buy it back in the form of expensive journal subscriptions; this is the essence of the scholarly publishing crisis.

The problem is that when content is behind a paywall, or is unaffordable, it is no longer widely available. This can have serious consequences for researchers' options for disseminating their work. It also has an enormous impact on the availability of research output to groups and institutions with limited budgets. The number of journals available for publishing their work has 
risen dramatically, but in many disciplines there are certain select journals that are considered the most prestigious and therefore desirable outlets. They also, not coincidentally, tend to be the most expensive to purchase, and therefore often not held by any but the largest institutions. As these cycles intensified over time, the conditions became ripe for the rise of the open access movement, in which journals and publishers make the content freely available to users.

Generally, authors publishing in open access journals retain the ownership of the content, and license it to be published under a Creative Commons license. In some "gold” open access journals, the author pays a page fee for the value-added services of quality control, discoverability, and so on. Other open access journals are free, often because they are subsidized through libraries, universities, or professional societies.

Choosing an open access journal for publication has been a courageous choice, as, until recently, these were considered less prestigious (and even rigorous), and therefore were risky choices for anyone seeking to boost their career. However, studies are now showing that publishing in open access outlets increases citation rates, although the perception of lower prestige remains among many researchers (Neugebauer \& Murray, 2013).

Nevertheless, the open access movement has been gathering strength, especially since the advent of the scholarly publishing crisis and the move toward open access in publishing. This has led to the widespread creation of research mandates from funders, institutions and publishers. Research mandates affect and designate researchers’ choices involving research outputs, both publications and data, usually in the direction that all outputs are made publicly available. Many 
funders have encouraged the move towards open access, and as we will discuss below, are also requiring publishers to allow copies of articles from funded research to be reposited (or remitted into a digital archive, i.e. repository) for open availability to the public. Funding mandates have also moved researchers toward more interdisciplinary work, and away from isolated research projects that exist within narrow confines of disciplines and locations. In addition, research mandates have driven the move in libraries toward providing research data support (Kouper, Fear, Ishida, Kollen, \& Williams, 2017). These mandates, their expansion throughout the research enterprise and their effects on researchers and libraries, are the central focus of this chapter. However, before we examine these issues from the perspectives of researchers, funders, institutions, and publishers, we will outline the basics of the research process and its cycles, so we can specify terms and meanings, and identify points of interest and entry for each stakeholder group.

\section{Understanding the Research Enterprise}

To understand the role of the library in supporting research, it is necessary to become familiar with the structure of research and research support. The process of research is a cycle of iterative discovery, but, particularly in funded scientific research, a research project with specific aims will eventually focus on a discrete question. A natural starting point to trace the process is that of the researcher or research team setting out to define and examine a question and/or test a hypothesis of interest. In general, a literature review is conducted to determine whether there is a gap in scholarly knowledge in the area. Researchers may also search to see whether others have 
been funded to examine the same or similar questions, but have not yet published their results (the site ClinicalTrials.gov, in which NIH-funded researchers must register trials as they begin, is a good example of a database that a clinical researcher might consult). If the "coast is clear" and the hypothesis appropriate to be tested, the researcher/team will develop and write a funding proposal in hopes of procuring funding for the project (the proposal is the request for funding, and is sometimes mistakenly called a grant; the grant is the actual monetary award for the purpose specified in the proposal). In most agencies and in most university settings, the lead faculty members or research team members writing the proposal are called primary investigators, or PIs. The PIs make a substantial investment of time and effort to produce the proposal, knowing there will be a small chance of success. Even for a proposals which are well-written, focused, and apply to an important new question, success rates remain low (for example, below 20\% in the NIH in FY 2016) and the environment "hypercompetitive” (Lauer, 2017). If the proposal is successful, then the grant is awarded. Below, Figure 1 shows these two major stages in the research process, and some of the professionals offering support throughout the process.

--[INSERT FIGURE 1 HERE]--

The proposal stage, as shown in Figure 1, includes proposal development processes and preaward compliance processes. The award stage, if the proposal is funded (or awarded the grant money) transitions the "pre-award" compliance processes into "post-award" grant processes. Many pre-award and post-award procedures have to do with compliance with the rules and regulations about how to meet requirements for grant accountability. These usually involve federal funding, which is mostly governed by regulatory authority in the Executive Branch, with agencies then producing rules, policies, and guidance, such as proposal filing procedures, public 
access policies, and ethical guidelines. Satisfying the abundant and complex compliance requirements (which go far beyond the research mandates we will discuss further in this chapter) may require substantial investment by organizations wishing to obtain research funding.

As mentioned above, no matter how advanced the grantsmanship and convincing writing skills of the PI, and no matter how competitive the proposal appears, there is no proposal that is assured successful funding. Researchers, as PIs, are usually more concerned about the proposal's competitiveness; however, the institution may be more concerned with the pre-award and post-award compliance (assuming that the proposal is competitive enough to get the award then award).

Organizations sponsoring research must have pre-award and post-award processes of some sort in order to receive grants. At many small institutions (with some exceptions), pre-award and post-award compliance assurance functions may be folded into the responsibilities of the budget or development offices. At most mid-sized and large institutions, there are generally multiple dedicated people working on these processes.

Generally, these professionals who oversee compliance and other related issues, are called research administrators, and can inhabit either departmentally-focused positions or more centralized administrative roles in a dedicated office for research administration. Departmental 
research administrators may handle both pre- and post-award functions, working directly in the same academic departments or units as the PIs. Administrators with a more centralized presence and institution-wide responsibilities work in an Office of Research, Office of Sponsored Programs (denoting research or other activities “sponsored” by a funding agency), Office of the Vice President of Research, or similarly named grants office. The centralized office functions tend to be divided into ethics (sometimes called “research integrity”), pre-award, and post-award roles. The ethics role includes overseeing and/or supporting the Institutional Review Board, and many other matters of ethics and safety; these can come into play both before and after awards, but also affect non-grant research processes on campus. Pre-award research administrators are responsible for making sure that proposals include all mandated elements of the funding agency, such as data management plans, biosketches, and budgets. Pre-award administrators also usually review the proposal's budget to be sure that the PIs have not promised obligations that the institution cannot accept. Post-award research administrators are responsible for making sure that everything that was promised is delivered, such as repositing of articles and following through on items such as data management and/or data sharing obligations. There are other primarily administrative tasks less relevant to librarians. However, there is also a strategic angle that libraries can support, working not only with the aforementioned research administrators but also with offices focused on the broader strategic development of researchers.

Proposal support for PIs is not mandated, but many mid-sized and large institutions are interested in improving their funding proposals to capture more grants, and decide that it is a wise investment to have some form of support for researchers to writing proposals (which often 
extends to researcher support, such as data management support, during the active post-award phase). These kinds of strategic offices usually employ research development and/or proposal development professionals who work with PIs to create more effective proposals.

These forms of institutional assistance to researchers are needed more than ever in the hypercompetitive environment outlined above. Recent intensification of funding agency pressures on institutions take three important forms: (1) development of/changes in federal mandates leading to funder requirements for more robust reporting and accountability; (2) development of/changes in federal mandates involving public access sharing of research and data; and (3) reduced levels of funding relative to the number of researchers requesting funding. These changes affect collaboration, post-grant administration, and the complexity of creating a competitive grant proposal. These pressures have motivated many institutions and units, including libraries, to find new ways to engage with and foster research. In the next four sections of this chapter, we will examine the varying perspectives and motivations of the four major players in the research enterprise: researchers, funders, institutions, and publishers. We will then discuss the effects these have on librarians and libraries.

\section{Researcher Perspective}

It is tricky to express how "researchers” approach the work of producing scholarly outputs from their work, as there are so many types of research (consider differences between the sciences such as physics and chemistry, clinical studies on medical interventions, social science studies on qualitative phenomena, humanities studies of documents or events, etc.). In addition, each 
research type involves varied types of data; these include computer files (spreadsheets, databases, coding, etc.), images, clinical or field samples, surveys, and many others. However, there are commonalities which can be instructive, and since researchers drive the entire scholarly ecosystem, we do well to focus on them.

Researchers generally share certain motivations. Foremost, they want to improve the knowledge-base of their discipline and advance human knowledge. Each discipline has its own values on how best to improve the world, but most researchers share the idea that new discoveries will contribute to a greater good. But there are also more immediate, practical concerns stemming from typically-competitive academic work environments. Researchers want their work to be recognized by peers in their field (often wanting peer recognition above institutional recognition, which can lead to some central challenges for institutional mandates). They want to gain tenure/permanent status, a sometimes fraught process in which publication of novel work in prestigious journals is an important achievement to demonstrate. They want their work to be widely disseminated and used, in particular as this might gain peer recognition and help assure them in securing future grant monies. In addition, they have an emotional attachment to their work, which can make it difficult for them to give up control of publications or data after being accustomed to exclusive access to them (Rice \& Southall, 2016).

These motivations can play out in various ways in the current research environment. Smith (2014) notes that scientific aims may not always harmonize with issues of legality or reproducibility. Pinfield (2015) notes that there are disciplinary differences in adoption of 
current trends in open access publishing and data sharing. Lange (2016) echoes this in her article on researchers in the field of management. As slow adopters of open access publishing (which is seen by many in that field as occurring in lower-tier publications), and likely creators of proprietary data, they can find themselves in a bind when mandated to share their publications and data openly. A particular challenge that Lange's subjects noted was the lack of open access publications in particular sub-disciplines. Deng and Dotson (2015) note that regarding data sharing, researcher concerns include "privacy, loss of ownership, fear of misuse, personal investment, reliable access, the adherence to the funders' mandate, metadata to increase exposure, and preservation development.” (p. 79)

Understanding these concerns and pressures is important for librarians who wish to reach out to researchers. This understanding, combined with outreach expertise, allows liaison librarians to build relationships with researchers. Liaison librarians should first show their understanding of these challenges, and then describe how they can ease some of the pressure through library supports.

An additional factor to note for librarians, and one which will be addressed below, is that the language used in research is very different from that used in libraries. Research has its own culture and norms for cultural appropriateness, which anyone seeking to engage with researchers must understand, if not master. 


\section{Funder Perspective}

As Briney, Goben and Zilinski (2017) note, funders (which can be from many sectors, but tend to be governmental, private (charitable foundations and other non-profits), or corporate) hope for many things from the funds they invest in research. These hopes typically stem from a desire to give back to the society (either the taxpaying general public or the charitable donors) that entrusts money and good faith in the funding organizations. These include: expanding access to research; increasing the speed of science; increasing the precision and accuracy of science through replicability/reproducibility; allowing taxpayers access to the research they have helped pay for; avoiding wasteful duplication of effort in this age of tight funding budgets; gaining a full return on investment by data re-use opportunities; increasing the chances of commercial benefits from the research and data produced; improving educational opportunities; and, making information available outside academia, and outside the United States (in the case of U.S. funders). As funding levels have decreased, competition for successful grants has increased, giving even more power to funding agencies. As scholarly content became less accessible over time giving rise to open access publishing, funders began to include public access mandates in their agreements. The U. S. government funding agencies originally were created to stimulate the public good; funders have become increasingly aware of the relationship between the public availability of the results of funded research and the potential for enhancing, for example, the economy in general. That potential for enhancing the economy through wider availability of data and research publications is driving some of the move toward mandating open access. While researchers seek to retain control over proprietary data and intellectual property, funders are taking a stronger stance in requiring public sharing, citing "compelling societal interests” (Ross \& Krumholz, 2013). As an example from clinical research, studies have found that half of 
funded clinical trials are never published (Ross \& Krumholz, 2013), and that there are information discrepancies between the entries in the ClinicalTrials.gov database and the publications resulting from the funded research (Becker, Krumholz, Ben-Josef, \& Ross, 2014). It is not surprising that funders have stepped in to take more control of their investments.

Therefore, in order to receive funding, researchers (and their institutions) must agree to share the benefits of funded research to the taxpaying public and facilitate future innovation and discovery by making research outputs publicly available. Public access plans in most sponsoring agencies cover publications (peer reviewed articles from funded research) and data (datasets from funded research). Although specifics vary, for government funding, publications must be placed (reposited) in a centralized database, such as PubMed Central, NSF PAR, DTIC Public, ERIC, etc., depending on the particular funding agency. This means that the methods, results, and conclusions drawn from funded research will be increasingly available online at no charge to the public. The ideal is that this will help to assure more equitable access to research findings. Public access mandates are an area where scholarly communications librarians, with expertise in open access principles and publishing policies, can be especially useful.

Public access mandates also include access to raw or minimally-analyzed data. Data management plans are required as part of the proposal, for all disciplines. Data repositing can be in local or disciplinary archives (whereas making them "available by request" or even "posted on the website” are no longer acceptable mechanisms). Data repositing mandates respect all compliance issues (regarding ethics, safety, intellectual property, export control, etc.), which 
ensures safety and privacy. They also allow researchers to protect their proprietary data when patents may be involved. Researchers must include archiving information and descriptions for reusability and long-term access, to ensure the data are as reusable as possible into the future.

There is some evidence, however, that funder mandates are easing somewhat; current trends lean towards reduced regulations and scaled-back restrictions towards seeking funding. At the same time, data librarians and other data management specialists have shifted towards increasing work in supporting data sharing.

\section{Institutional Perspective}

As outlined above, institutions have interests in demonstrating the amount and quality of the research outputs they support (and their support is significant). Furthermore when government grants are awarded, the funding award is to the institution and responsibility for completing the research and complying with award mandated lies ultimately with the institution. Therefore, most of the trends related to institutional mandates center around the institution's need to comply with funding mandates. As already discussed in the earlier section on the research enterprise, there are many points at which institutions provide infrastructure and staffing to enable researchers to do their work. In some sense, research institutions and universities exist to support research and the creation of new intellectual advances, but they also have educational and service missions, and those are well-served by having a prestigious research profile. Even teaching-focused institutions that exist to support the educational mission often see research as a 
means to improving their reputation as well as ensuring that their teaching is engaged with new discoveries and innovations. Furthermore, as undergraduate research becomes more important as a high-impact practice (listed by the AAC\&U as a practice that has a "high impact" on students’ cumulative learning (Association of American Colleges \& Universities, 2008)), institutions (and funders as well) are pushing the boundaries of how research and inquiry can be inculcated into the undergraduate learning experience. As a result, data management and even publishing are becoming part of the baccalaureate experience instead of being restricted to the graduate and faculty experience.

Beyond educational, research, and service contributions to society, institutions also look for return on their investments, both reputational and financial. Therefore the institution seeks to: prevent public relations damage in instances of research misconduct, such as if data are found to be missing or fraudulent; improve opportunities for commercialization, which may include support for documentation and other aspects of patent applications and also protections for intellectual property; and encourage reuse of research outputs in the service of education and support of early-career researchers (Briney, et Al., 2017).

In the recent era of pressure towards open access publication, data sharing, research reproducibility, etc., institutions have entered the realm of issuing mandates related to research conduct and outputs, for many of the reasons outlined above. The push towards openness will have long-term impacts and libraries, even with the rise of research data management support services, cannot manage this trend alone: responses must be cross-functional and institutionally 
created and supported (Reilly, 2014; Plutchak \& Kaplan, 2016). To this end, almost half of higher education institutions have formal research policies (Briney, et al., 2017), and in fact higher education's support of the costs, infrastructure, compliance tracking, and communication required for open access is crucial to its success (Pinfield, 2015).

Some rough spots remain. As noted above, researchers tend to be more invested in their discipline's culture and norms than that of their institution. Another issue is that there is a delicate balance between encouragement and enforcement, or, more bluntly, the carrot and the stick. Some say that if institutions want researcher participation in repositing publications, data and other research outputs in institutional repositories, they should "show that they mean it" (Neugebauer \& Murray, 2013), but others promote the idea that a punitive approach to members of the institution's own community is counterproductive (SPARC, 2016). It may be that recognition for compliance is a better incentive.

Furthermore, in addition to monitoring and using their own research products, institutions are consumers of those of others, and so far have paid top dollar for them, in the form of publisher fees. With the advent of open access in publications, the academy has the chance to get out from beneath the constraints and costs of commercial interests (SPARC, 2016; Steele, 2014). However, it will take an investment up front: in the short run, institutions must simultaneously pay for publisher content at the same time as supporting new publishing models such as libraries acting as publishers themselves. This will be true until open access becomes the norm and most content is available freely. 


\section{Publisher Perspective}

Before delving into the perspective of publishers (itself a widely diverse group), it is helpful to understand the two main possible avenues toward meeting mandates regarding open access publication. Articles are made available through gold or green models (along with hybrid forms, and variations within these two categories). "Gold OA makes the content immediately accessible, but unsubsidized journals often charge authors article processing charges (APCs) paid out of grant funds. Green OA typically involves publication in subscription journals and deposits a version in an OA repository that is often subject to a publisher embargo that delays access to the open version.” (Chadwell \& Sutton, 2014, p. 226) Issues arise when funder mandates specify that grant funds cannot be used for APC charges (which can go up to $\$ 3000$ per article, and which are sometimes paid by institutions), or that specify shorter embargo periods than those allowed by the journal of interest.

Any librarian who has had to cut resources desired by users in favor of continuing others at what seem like ever-increasing publishers’ prices may have mixed feelings for the world of publishing, but publishers bring many positive contributions to the world of the research enterprise and the library. Publishers add value in the form of maintaining editorial and content standards, managing dissemination and production, and increasing discoverability of content (Mangiafico \& Smith, 2014). They also may be the arms of scholarly societies, which have a vested and usually altruistic interest in making sure that new disciplinary scholarship reaches constituents. Many for-profit publishers have contracts with not-for-profit scholarly societies to 
produce their society journal at a more modest cost than purely for-profit journals. The existence of the green and gold models outlined above are evidence that publishers are attempting to adjust to the reality of mandates' affecting the research outputs of the authors, whose content is their bread and butter.

Furthermore, publishers often host additional content such as multimedia supplements or archived datasets. Publishers are increasingly requiring that research data be submitted along with any publication, and in fact some journals now are “data journals”, highlighting data sets and their use as opposed to research outputs. All of this stems from publishers' interests in: research reproducibility; content being available for scrutiny which will expose problematic research; and enhanced journal reputation (along with diminished retraction rates) (Briney et. al, 2017). These feed into sustainability for individual publications and for the industry.

Two “disruptive forces” of note, beyond that of open access mandates, have entered the traditional world of publishing. The first is the change in review types and standards brought about by the open access journal PLOS ONE, now the largest journal in the world. "[PLOS] accepts papers... which are peer reviewed to assess their "soundness” rather than on any assessment of "importance" or "novelty" (criteria deemed to be more subjective but important in selection for most traditional journals). This new phenomenon reverses journal publishing trends of the last 50 years characterized by ever greater specialization, and is therefore a disruptive force in the publishing market.” (Pinfield, 2015, p. 618). The other is the advent of libraries entering the publishing market as publishers. This is a natural outgrowth of their role, at many 
institutions, of hosting institutional repositories for publications and data (Day, Casey, \& Wolfe, 2015). In fact, "though publishing is a new area of work for libraries, it is often a natural outgrowth of their existing infrastructure and skill sets, leveraging the institutional repository as publishing platform and repositioning librarians’ skills as information managers.” (Lippincott, 2016). As a result, many libraries are now hosting journals on the institutional repository or other open access systems, and managing the infrastructure for faculty to conduct peer review and editorial tasks to publish journals.

\section{Challenges Affecting Libraries and Librarians}

So far this chapter has outlined general trends and impacts of the changing research landscape, and mandates from funders, institutions, and publishers. This context is complex, and needs to be well understood for libraries and librarians to take effective action. We will now focus in on libraries and librarians in particular (although some of the impacts are implicit in the trends already described) — the challenges these developments have raised and continue to raise for them, and interventions which have proven to be successful.

For a start, none of the changes outlined here are beyond the reach of our core skills, as long as there is sufficient support for continuing education and concentration on new roles. Librarians bring inherent perspectives in traditional concepts of information documentation and retrieval, archival principles, and descriptive classification. These provide the essential foundation that has led to libraries taking on new modes of research support. Newer (relative to archiving and organizing information) skills around instruction and outreach provide especially valuable 
additions to the library skillset. Added to this, recently emerged competencies such as digitization, metadata creation, scholarly communications, and data management provide specialized direction to these traditional skills, while fundamentally building on the basic information and documentation principles on which librarians have always relied. Keeping these skills highly relevant and trying to adjust to changing trends in research priorities and technological changes can be extremely daunting in the face of shrinking budgets, lean staffing, and lack of institutional power.

Another challenge is the addition of data services to the more traditional library offerings. This has become common for most institutions with a large research presence, but the transition has not necessarily been smooth. Working with and consulting about raw data - as opposed to data tables traditionally found in almanacs, government reports, and the like - is uncharted territory for many librarians. As Plutchak and Kaplan (2016) note, “data is the new bacon”-we want more and more of it!_ but, “publications are easy—data is the real beast” (p. 15, p. 18). It takes institutional support, staffing, and budget to move into offering data services as part of research support, let alone (and more intensively) developing approaches to datasets as akin to publications (e.g cataloging them, publishing them in data journals, etc.). It may help researchers if librarians develop data taxonomies, or help with attribution-stacking (how to cite the results of combining separate datasets, each of which has a separate attribution) (Smith, 2014). Many libraries and librarians have had to create those offerings without the requisite support, staff or funds, and it creates intense pressures, especially on those staff with more datafriendly skills and proclivities, if specialized staff are not hired. 
This and similar situations highlight the sometimes-uneasy position of libraries in the larger context of their organizations. As their collections are increasingly fully available on users' desktops, the connection with the physical collection and physical place weakens. This "semioutsider" status can be useful, as libraries and their staff are able to be neutral and interdisciplinary actors (Partlo, 2014), but it also can mean that there are concerns about institutional support and status, and fears that the libraries' role may be misunderstood and relegated to the back waters of organizational politics. Communication styles and terminology can be an issue as well, varying as they do between library and research contexts. And, those libraries that are active players in the research and data support arenas in their institutions are squeezed between the demands of top-down drivers (external, funders) and bottom-up drivers (internal, institutional) (Rice \& Southall, 2016).

Libraries and librarians also, as they have with user groups throughout history, feel challenged by researchers' lack of awareness of their services and abilities to assist in the research enterprise, as well as their contributions to the intellectual life of the institution. Part of this lack of awareness may rest with the language and cultural barriers between libraries and researchers, while part of this is the "out of sight, out of mind" phenomenon (if I do not go to the library (and I never go in person anymore), it does not exist). Part of it may also be general (and normal!) resistance to change, and if libraries are placed in roles of enforcing compliance with research mandates, they will not be popular with many researchers. Instead, librarians want to be part of the researcher experience - and would even benefit from showing that they do research themselves - to emphasize the role of librarians as partners. The scope of researcher needs in the new landscape of mandates is bewildering for everyone, and researchers feel this administrative 
burden and steep learning curve acutely. Researchers may need to have assistance with things such as obtaining uniform identifiers (ORCIDs and similar) for funding, biosketches and CV management, identification of metrics for proving qualifications and seeking collaborations, strategies for performing interdisciplinary literature reviews, and even implementing best practices for data management tasks such as documenting, storing and preserving data. However, they do not necessarily look to the library or even to data services provided on campus for such assistance. This intensifies the pressures on libraries and librarians to increase and focus outreach and instruction efforts. The liaison model that has served us for decades can evolve to include research, but may need to be continually revisited and reworked.

A further challenge in the age of research mandates is that of developing collaborations. Particularly where librarians are producing research and publishing as faculty, librarians can provide valuable partnerships by bridging multiple disciplines through the interdisciplinary information perspective. Mandates from all sources, but especially those from funders, are placing emphasis on the need for interdisciplinary work. This is new territory for researchers, while not so much for librarians, who can, and do, cross disciplinary boundaries frequently; this situation calls into play librarians' skills as translators, both between disciplines, and between the research and the mandate context, and may smooth the way to effective partnerships. Other collaborations, which are necessary in the new era of mandates, are with research administrators and similar offices, in order to be able to present a unified set of content regarding mandate requirements and compliance issues. 


\section{What Works}

Finally, we turn to what libraries and librarians can do to support their constituents—researchers and institutions — in the age of research mandates and rapid change in the research landscape. First, Figure 2 shows ways in which librarians can support researchers at each point in the research process. Libraries are working on programs and policies to address every point in the inner circle of the research process (presented simply here, but actually often a complex set of interrelationships).

\section{--[INSERT FIGURE 2 HERE]--}

The increase in mandates and grant competitiveness also means that any services that help researchers develop stronger proposals can be considered responses to these new funder, institution, and publisher requirements. The interventions listed here are not meant to be exhaustive; rather, they illustrate the range of services offered in this new era, leaving libraries to choose what fits their setting and users best. The takeaway here is that librarians should, as mandate-creators do, engage with researchers at every stage of the research life cycle: from gap analysis; to the pre-experiment work of proposal writing, to data management support, to identifying publishing options, hitting every point of this cycle. It is also helpful to understand the differences in the nature of research cycles for different disciplines; outreach efforts should concentrate on disciplines with slower adoption of practices that are necessary in order to comply with mandated activities. Some disciplines such as the health sciences have been working through the early changes in funder mandates, and therefore have well-established ideas of how to adapt to these changes. Other disciplines, such as agriculture and energy, are being affected by the expansion of public access mandates across all funding agencies. These newly-affected 
disciplines will need extra efforts to reach out and remind researchers of the roles that the library can play.

Therefore, as we have considered above, no one wants suite of services with few or no users, and the best way to build a user-base is to build relationships (Neugebauer \& Murray, 2013). To some extent this is part of general outreach efforts, and at first librarians may have to ease these offerings into outreach by mentioning research support during existing activities and programs. By soft-launching research support discussions into existing outreach work, librarians can begin to gauge interest and raise awareness. One of the advantages of research support is that it can be offered in conjunction with existing work to get the conversation started. Early stages of support may need to be modest and focused on demonstrating to departmental partners that librarians’ skills transfer into the research realm.

To transition existing support activities into a robust suite of services, relationship-building needs to be targeted and intense. The idea is that libraries should be the place researchers turn to if they need assistance; they are likeliest to do this if they trust the skills and expertise of librarians and library staff. An effective strategy to accomplish this is to be embedded in research departments and projects (and if possible, get in on project involvement in its early phases) (Rice \& Southall, 2016). Health sciences librarians have been supporting their clinical researchers in this way for over a decade, and in fact funding to staff the role of informationist is now written into many such research grants. (For a detailed and explicit list of library support activities related to each of a wide range of key function areas in clinical research, see the article 
titled "Library-based clinical and translational research support” (Holmes, Lyon, Johnson, Sarli, \& Tennant, 2013)).

While embedded research librarianship may not be practical or even possible for most library staff models, re-envisioning librarianship requires, if not the in-depth understanding of being in daily close contact with research projects, then at least an understanding of the authentic research process (outlined earlier in this chapter). To this end, librarians should seek opportunities to become more familiar with the research enterprise. This could take the form of completing one of the many excellent online research data management and research publication trainings (the University of Edinburgh's MANTRA course being one of the better known). Librarians should consider attending any workshops offered by other research departments and offices on campus, partly to become familiar with the content, and partly for networking opportunities. Webinars and recorded presentations may also be an option; many of the federal funding agencies offer live or recorded webinars in order to help researchers and research administrators learn about their agency. One option is to look at agency websites and Youtube ${ }^{\mathrm{TM}}$ channels to see if there are trainings offered; another is to sign up for agency newsletters to receive announcements of future webinars. In addition, many research sites host visits from agency representatives; it is worth attending any such visits at your site, and/or to search for recordings of agency visits or talks from expert faculty given at other institutions. Again, Youtube ${ }^{\mathrm{TM}}$ and other video platforms are excellent places to watch older videos and get a feel for how the agencies talk to the research community. Another important continuing education activity is to read federal guidelines and become familiar with the structure of funding opportunities (in fact, the library may even consider applying for a federal grant itself). 
Once research liaisons are familiar with the research structure and landscape in general, a good next step is to focus in on how research administration is conducted in the specific institution. As discussed above, large organizations and universities will generally have a complex infrastructure around the research funding process. Even smaller campuses often have multiple professionals working full-time to support faculty in getting and administering grants. Understanding who these professionals, are, their roles, their professional concepts and jargon, the offices in which they work, and the relationship of those offices to the library, is a valuable way to start forming partnerships.

Once connections have been established between the research administration and administrators and libraries and librarians, librarians can not only learn from administration, but also offer a new range of resources and support to the people who support the research enterprise. There are myriad ways in which libraries can support institutional goals and research mandates beyond directly supporting researchers; see Figure 3 for a number of library responses to institutional missions which may involve such mandates.

--[INSERT FIGURE 3 HERE]--

Not surprisingly, there is considerable overlap between Figure 2 and Figure 3. Libraries may see their services to the two different constituent groups, the institution and the researcher, as quite similar, but they need to remember that the perspectives of these two groups are quite different, and service offerings need to be framed and publicized with that in mind. For example, research 
development (RD) professionals tend to be interested in training and consultations for themselves and for PIs, and in creating teams that can work on more complex large grants. Both libraries and RD teams are interested in outreach and partnerships for better engagement. Both are interested in offering workshops and training to improve research skills. Both work across disciplines. And both have an interest in data and the literature - librarians from an information and scholarship perspective and RD teams from a grantsmanship perspective. As a result, these $\mathrm{RD}$ offices can be very librarian-friendly, and approaching them involves a focus on their shared interests around workshops and consultations.

Another example is that units that work with researchers on their proposals and compliance issues may offer the best access to researchers. Because researchers must submit proposals and execute grants through Sponsored Research or Research Administration teams, they may be the first place they think of when planning a new research project, making these teams excellent partners for libraries. Approaching them should focus on compliance and how librarians can help research administrators understand and track compliance issues around public access mandates.

When building relationships with these offices, it is good to remember that the grant milieu is in many ways like any other subject area. It depends on information, so libraries have a surprisingly wide range of assistance to offer to research administration teams. The same strategies that are successful in liaison librarianship apply here: reach out, be persistent and supportive, and work to understand the specialty information of the world of which the team members are part. An important strategy is to offer specific assistance. It is not effective to say, "let us know how we can help you in your work"; instead, offer specific ideas for areas of 
support and program topics. For example, in the case of outreach to RD offices, the research liaison librarian might approach the team with the query, "We're interested in helping your proposal development. Maybe we could partner to offer training on dissemination metrics or data management?” Another example is that the librarian might ask a departmental or post-award research administrator, "I know there are new rules about public access to data and articles. Would you like to talk about how we can help with post-award public access compliance?”

Perhaps the most critical thing to keep in mind is that library-centric terminology and perspectives are not well-understood by non-librarians. This means that librarians need to be constantly thinking about how to translate terms related to library functions into partners’ words, contexts, and cultures. Partlo (2014) likens this process to translation of languages. Just as GoogleTranslate only works to an extent (it does not carry nuances of meaning or culture through to its translations), communicating to researchers will be more effective if librarians can go beyond terminology. To do that, librarians can start with the researchers’ perspectives, and frame services in a way that fits their goals and understanding. For example a research liaison might ask, “Can I help you with your post-grant dissemination? I’d be happy to consult with you on preserving your publications and helping to make them more discoverable.” By giving a specific example, librarians help our researchers to break out of the mindset that libraries are about books and are not in touch with the modern research context. This translation function may be particularly important when working with interdisciplinary teams; while a librarian may not be "fluent" in the researcher's disciplinary "language", s/he is likely more fluent in another discipline’s language than the researcher is, and can serve as a bridge to understanding (Partlo, 2014). 
If liaisons can be adept at translation, and can be trusted partners in the research enterprise, it is more likely that librarians will be invited into conversations about researchers' needs. To the extent possible, given staffing and funding, customizing services for different disciplines and research teams can be effective ways to build on existing relationships and offer services that are targeted and effective. An example is the mediated deposit service developed to support researcher self-archiving described by Neugebauer and Murray (2013). In fact, the development of library research data services in response to early funder mandates can be seen as a kind of customized service, as are instances of libraries taking on institutional repositories for publications and data, and becoming publishing arms of the university (sometimes reinvigorating university presses). Another example is the scholarly communication coaching service outlined by Bruns, Brantley and Duffin (2015); their article includes a brief scholarly communication coaching toolkit.

Offering these customized services will often mean that librarians must take on new roles, for which they may not have training (or even, initially, time). Researcher response to these innovations is generally so positive that the original investment is considered well spent, but it is important that there are mechanisms in place in libraries to support staff around new duties, capacity, and the potential for burnout. Administrative advocacy is a necessary adjunct to increased research work. In return, a growing reputation for high quality library-provided research services gains increased support for and recognition of the library. If demand is high, it may help to incorporate librarians into funded teams to streamline their involvement, as well as 
implementing other strategies to ease time pressures. Otherwise, the most time-intensive offerings may have to be curtailed.

Libraries without the capacity to offer customized services should not give up on research support, however. Focusing on ways to provide information that can be created once and re-used and re-purposed is often possible for libraries facing time and staffing shortages. A time-efficient activity is for librarians to gather tools, such as reporting templates, which may prove useful in helping researchers meet research mandates of all sorts. Many of these can be found in the literature around research data management, and professional organizations and listservs regularly feature programs and messages relating to new innovations and resources. Some examples are DOAJ (the Directory of Open Access Journals), SHERPA-RoMEO (a database of publishers' policies on copyright and self-archiving), SHARE and CHORUS (one an academiccreated and the other a publisher-created resource, each centered around tracking and meeting mandates for open access) (Plutchak \& Kaplan, 2016), ROARMAP (a searchable international registry charting the growth of open access mandates), and Authors Alliance (“a non-profit organization, to help authors share their work in a digital environment in order to serve the public good” (Steele, 2014)).

\section{Conclusion}

One of the most fascinating aspects of delving into the myriad topics which have been covered in this chapter is to encounter the visions for the future in this radically and rapidly changing landscape. We have seen how "the extension of support now provided by the library is radically 
redefining the relationships [libraries have] had with our research community” (Walters, 2016) and in turn how "the research environment reconfigures the library” (MacColl, 2010). We have seen how libraries, despite challenges related to funding and staffing, have stepped up and created services and programs that assist their researchers and institutions at many stages in the research life cycle. We have even seen libraries taking on completely new roles as data repository hosts and managers, and publishers. What new trends will libraries encounter in the future? How can libraries become "masters of their domains” with distinct missions? (Mangiafico \& Smith, 2014)

Several themes emerge from the literature. First, libraries are ideally positioned to support and advance the open access movement, which may uncouple the research enterprise from the control of commercial publishers. We librarians, given our backgrounds in scholarly communications management and financial negotiation, may be able to take active roles in institutional responses to national systems, and drive cross-institutional collaborations (Key Perspectives, 2009; Chadwell \& Sutton, 2014). We should look for opportunities and strategies for embedding values of open access in our academic cultures as we find them. (SPARC, 2016) Next, libraries and librarians should commit to current awareness of trends in research publication and data management. It is not enough to scan published literature, which has a substantial lag time (as we well know) between production and publication; we need to regularly scan list-servs, social media, etc. We need to shift our self-identities as well; we are already well into the new era of libraries not as collection managers but as disseminators of scholarly outputs. If, as looks likely, these dissemination avenues eventually will all be open, it will be up to us to make them findable through mechanisms such as cataloging (Jubb, 2012; Webster, 2012). What 
forms will research outputs take in the future, and what will our roles be vis-à-vis those outputs?

There are already strong movements towards treating data as we would publications: citing them, repositing them, encouraging their use as scholarly indicators, and having data journals that highlight data sets rather than research outputs. In future, some authors believe, there will no longer be journal articles at all, but only data, with peer review occurring post-publication (Steele, 2014).

In addition, we must pay attention to the training — and perspectives—of the next generation of librarians. Information schools need to be offering training that readies graduates for multiple roles in shifting professional territories. An important example is that of rapid shifts in technologies that libraries must be able to incorporate-- into how they assist patrons, and how they conduct their own operations. It is naive to expect that the technologies that information science students learn now will be relevant in even a year or two, but the spirit of inquiry around adoption and learning of new tools and online modalities can serve library professionals well. Rather than teaching the technologies, information schools can focus on questions such as: What does it mean to be technologically agile and how can those skills be enhanced? What are best practices in terms of identifying and learning new technologies? What is necessary to maintaining technological skillsets in the face of new developments? How should library professionals evaluate what new technologies are worth investing in vs. just "flashes in the pan”? How should technologies be adapted to different settings, user groups and needs? And, at least for now, what are the implications of digital divide? These questions should be explicitly woven into course work, internships, etc. as appropriate. The goal should be not to create IT professionals, but rather IT appreciators (Partridge et al, 2010). 
Technology, of course, is not the only area in which curricula need to be responsive to the everincreasing pace of change; the area of scholarly communications is another central one. They are similar in that both straddle the border between skill content and intellectual content. In the larger sense, information schools must make strategic decisions as to what balance they wish to strike between these two sides (Partridge et al., 2010; Chow et al, 2011). In the area of scholarly publishing, this may take the form of teaching both the skills sets of web publishing and research skills, and the intellectual content inherent in topics such as research ethics, librarian's roles in outreach and support, and the like. It is worth considering that as seminars and electives on trends in scholarship are emerging at many schools, practicing librarians may want to consider attending, not only to get a broader conceptual view of these trends, but also to offer their own perspectives and enrich these courses and seminars. Furthermore, it is well for librarians to offer library students practical advice, telling them what topics are important on the market and helping to guide them to these courses on emerging trends. The educational environment is enriched when the whole profession is engaged with it.

In reality, the extent to which libraries can keep pace with these rapid changes depends on, once again, staffing and funding, to which we add the element of institutional will. Rice and Southall, in their excellent work “The Data Librarian’s Handbook”, consider whether libraries need a reboot. In the end, they suggest a path of action, which can be done by any librarian, and any library, if they are willing to commit to it. "The key to success in providing modern research support may be in thinking of researchers as partners and collaborators, and in getting them to view us in the same manner. In this way we exit our rosy comfort zones in a spirit of 
entrepreneurship and adventure, offering not just our existing knowledge but also a willingness to learn new things and tap into an expanding network of knowledgeable peers. If librarianship can change, surely librarianship can too.” (Rice \& Southall, 2016, p. 158). This advice may leave us uncomfortable, but it is powerful and simple. For those of us who have further to go in our engagement with our researchers, it is time for us to consider change in this direction; if we have the will, surely we will succeed.

\section{References:}

Association of American Colleges \& Universities. (2008). High-impact educational practices: A Brief Overview. In: High-Impact Educational Practices: What They Are, Who Has Access to Them, and Why They Matter, Kuh, G.D.. Retrieved from https://www.aacu.org/leap/hips .

Becker, J. E, Krumholz, H. M., Ben-Josef, G., \& Ross, J. S. (2014). Reporting of results in ClinicalTrials.gov and high-impact journals. Journal of the American Medical Association, 311 (10), 1063-1065.

Briney, K., Goben, A., \& Zilinski, L. (2017). Institutional, funder and journal data policies. In: Curating Research Data: Volume 1, Practical Strategies for Your Digital Repository, Johnson, L.R. ed. Chicago: Association of College and Research Libraries.

Bruns, T., Brantley, S., \& Duffin, K. (2015) Scholarly communication coaching: Liaison librarians' shifting roles. In: Partnerships and New Roles in the 21st-Century Academic Library: Collaborating, Embedding, and Cross-Training for the Future, Eden, B.L., ed. London: Rowman \& Littlefield.

Chadwell, F., \& Sutton, S. C. (2014). The future of open access and library publishing. New Library World, 115 (5/6), 225-236.

Chow, A.S., Shaw, T.L., Gwynn, D., Martensen, D. \& Howard, M. (2011). Changing times and requirements: Implications for LIS education. LIBRES Library and Information Science Research Electronic Journal, 21(1), 1-23.

Day, J., Casey, A. M., Wolfe, C. (2015) The library as publishing house. In: Creating Research Infrastructures in the $21^{\text {st }}$-Century Academic Library, Eden, B.L., ed. London: Rowman \& Littlefield. 
Deng, S., \& Dotson, L. (2015) Redefining scholarly services in a research lifecycle. In: Creating Research Infrastructures in the $21^{\text {st }}$-Century Academic Library, Eden, B.L., ed. London: Rowman \& Littlefield.

Holmes, K .L., Lyon, J. A., Johnson, L. M., Sarli, C. C., \& Tennant, M. R. (2013). Library-based clinical and translational research support. Journal of the Medical Library Association, 101 (4), 326-335.

Jubb, M. (2012). The scholarly ecosystem. In: Academic and Professional Publishing, Campbell, R., Pentz, E., \& Borthwick, I., eds. Oxford: Chandos Publishing.

Key Perspectives, Ltd. (2009). A comparative review of research assessment regimes in five countries and the role of libraries in the research assessment process. Report commissioned by OCLC Research. Retrieved from http://www.oclc.org/content/dam/research/publications/library/2009/2009-09.pdf .

Kouper, I., Fear, K., Ishida, M., Kollen, C., \& Williams, S. C. (2017). Research data services maturity in academic libraries. In: Curating Research Data: Volume 1, Practical Strategies for Your Digital Repository, Johnson, L.R. ed. Chicago: Association of College and Research Libraries.

Lange, J. (2016). Scholarly management publication and open access funding mandates: A review of publisher policies. Ticker: The Academic Business Librarianship Review, 1 (3), $15-27$.

Lauer, M. (2017). FY 2016 by the numbers. National Institutes of Health Office of Extramural Research. Retrieved from https:/nexus.od.nih.gov/all/2017/02/03/fy2016-by-thenumbers/.

Lippincott, S. K. (2016). The library publishing coalition: Organizing libraries to enhance scholarly publishing. Insights, 29(2), 188-191.

MacColl, J. (2010). Library roles in university research assessment. Library Quarterly, 20 (2), 152-168.

Mangiafico, P., \& Smith, K. L. (2014). Reason, risk and reward: Models for libraries and other stakeholders in an evolving scholarly publishing ecosystem. Cultural Anthropology, 29(2), 216-235.

Neugebauer, T., \& Murray, A. (2013). The critical role of institutional services in open access advocacy. International Journal of Digital Curation, 8(1), 84-106.

Partlo, K. (2014). From data to the creation of meaning Part II: Data librarian as translator. IASSIST Quarterly, 38(2), 12-15.

Partridge, P., Lee, J., \& Munro, C. (2010). Becoming “Librarian 2.0”: The skills, knowledge, and attributes required by library and information science professionals in a web 2.0 world (and beyond). Library Trends, 59(1-2), 315-335. 
Pinfield, S. (2015). Making open access work: The "state-of-the-art" in providing open access to scholarly literature. Online Information Review, 39(5), 604-636.

Plutchak, T. S., \& Kaplan, L. (2016). A library perspective: Data wranglers in libraryland: Finding opportunities in the changing policy landscape. The Serials Librarian. 70 (1-4), 14-25.

Reilly, S.K. (2014). Rounding up the data: Libraries pushing new frontiers. Learned Publishing, 27, S33-34.

Rice, R., \& Southall, J. (2016). The Data Librarian’s Handbook. London: Facet Publishing.

Ross, J. S., \& Krumholz, H. M. (2013). Ushering in a new era of open science through data sharing: The wall must come down. Journal of the American Medical Association, 309(13), 1355-1356.

Smith, M. (2014). Data governance: Where technology and policy collide. In: Research Data Management, Ray, J.M. ed. West Lafayette, IN: Purdue University Press.

Scholarly Publishing and Academic Resources Coalition (SPARC). (2016). Open access and research funders: A report on challenges, opportunities, and collaboration. Retrieved from https://sparcopen.org/wp-content/uploads/2016/04/RWJF-SPARC-publicreport.pdf.

Steele, C. (2014). Scholarly communication, scholarly publishing and university libraries: Plus ça change? Australian Academic \& Research Libraries, 45(4), 241-261.

Walters, D. (2016). Managing mandates. Serials Review, 42(2), 131-134.

Webster, K. (2012). The evolving role of libraries in the scholarly ecosystem. In: Academic and Professional Publishing, Campbell, R., Pentz, E., \& Borthwick, I., eds. Oxford: Chandos Publishing.

Zbylut, D. J. (1992). Indirect costs: The past, present, and a possible institutional response. SRA Journal, 24(3), 13-18.

\section{Appendix 1:}

Changing and recent federal mandates, and how libraries can help researchers address them 


\begin{tabular}{|c|c|}
\hline $\begin{array}{l}\text { Data management in all agencies and } \\
\text { disciplines }\end{array}$ & $\begin{array}{l}\text { DMPtool training \& assistance } \\
\text { - Data-focused repository help } \\
\text { - Consulting on data cleaning, description, } \\
\text { and metadata }\end{array}$ \\
\hline Study repositing & $\begin{array}{l}\text { - } \text { Data management } \\
\text { - } \text { Repositing, description, and linking in } \\
\text { clinicaltrials.gov }\end{array}$ \\
\hline $\begin{array}{l}\text { Dissemination } \\
\text { and } \\
\text { Public Access for journal articles }\end{array}$ & $\begin{array}{l}\text { - Advice on open access, choosing journals, } \\
\text { licenses, etc. } \\
\text { - Assistance repositing in public-access } \\
\text { repositories operated by the government } \\
\text { agencies (Pubmed Central; NSF PAR; } \\
\text { DTIC; etc) } \\
\text { - Compliance tracking and linking } \\
\text { - Classification and descriptive metadata }\end{array}$ \\
\hline Biosketches & $\begin{array}{l}\text { Building a SciENcv collection, including } \\
\text { using accurate field-specific descriptors } \\
\text { - Searching for articles and strategically } \\
\text { choosing the right article for each } \\
\text { proposal }\end{array}$ \\
\hline
\end{tabular}

Evaluation and impact assessments

- Identifying appropriate metrics to demonstrate impact of research 
- Templates for how to apply metrics as a way of demonstrating expertise

\section{Federal trend or current agency debate Library support offering}

Reflecting multiple disciplines in the

literature

Identifiers

Broadening of impacts
- Interdisciplinary push - helping researchers find the foundational literature in relevant other disciplines

- Citation management

- Setting up ORCID and explaining the benefits

- Helping researchers curate their online

CVs, especially when authority control is hard

- Possibly coming soon - uniform funding identifiers

- Searching literature about potential value of the grant in disciplines where the PI not expert 
Figure 1: Grant proposal and award process

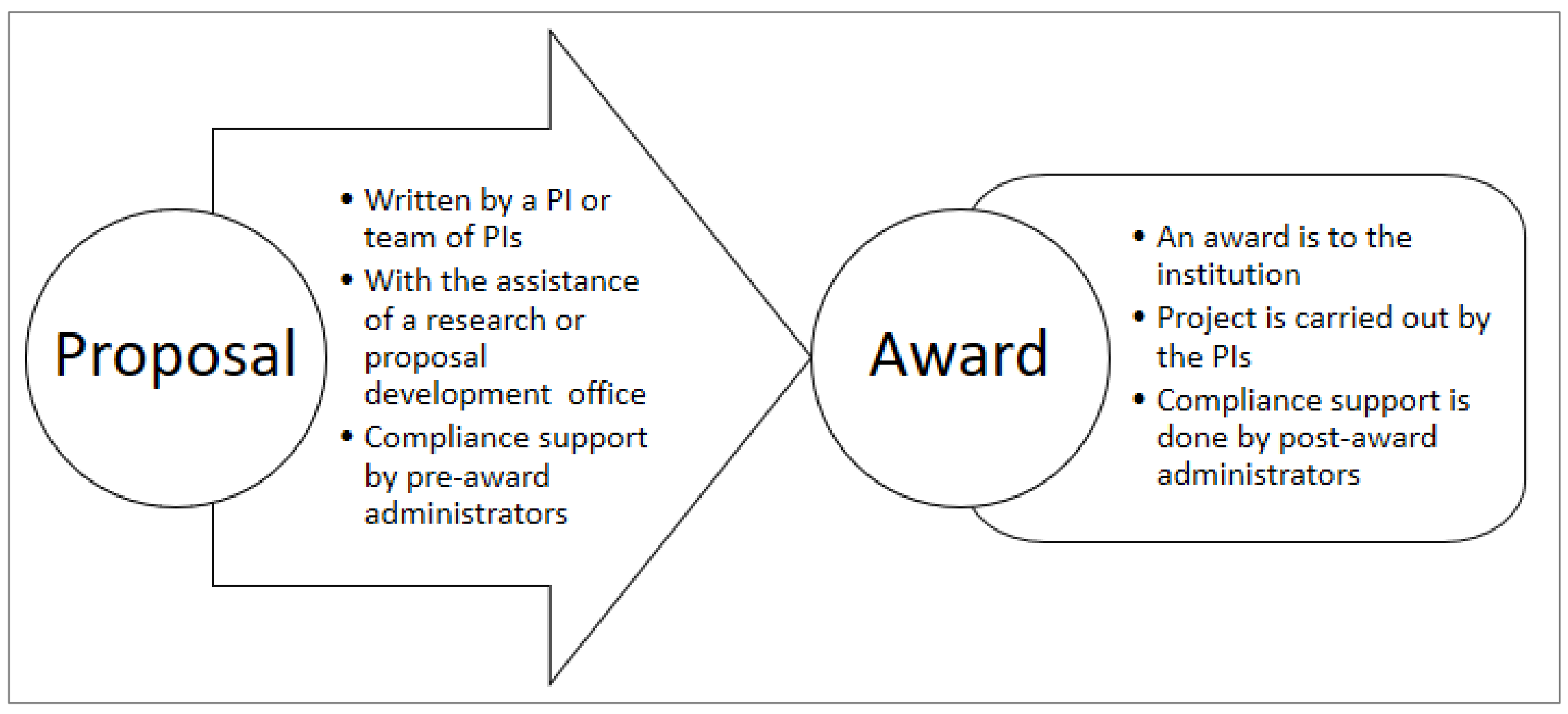


Figure 2: Ways librarians can support researchers

- Purchase subject-specific resources

- Information literacy training and support

- Collaborative communication and relationship-building

- Assist with literature searches and search strategies

- Assist with gap analyses and identifying potential topics
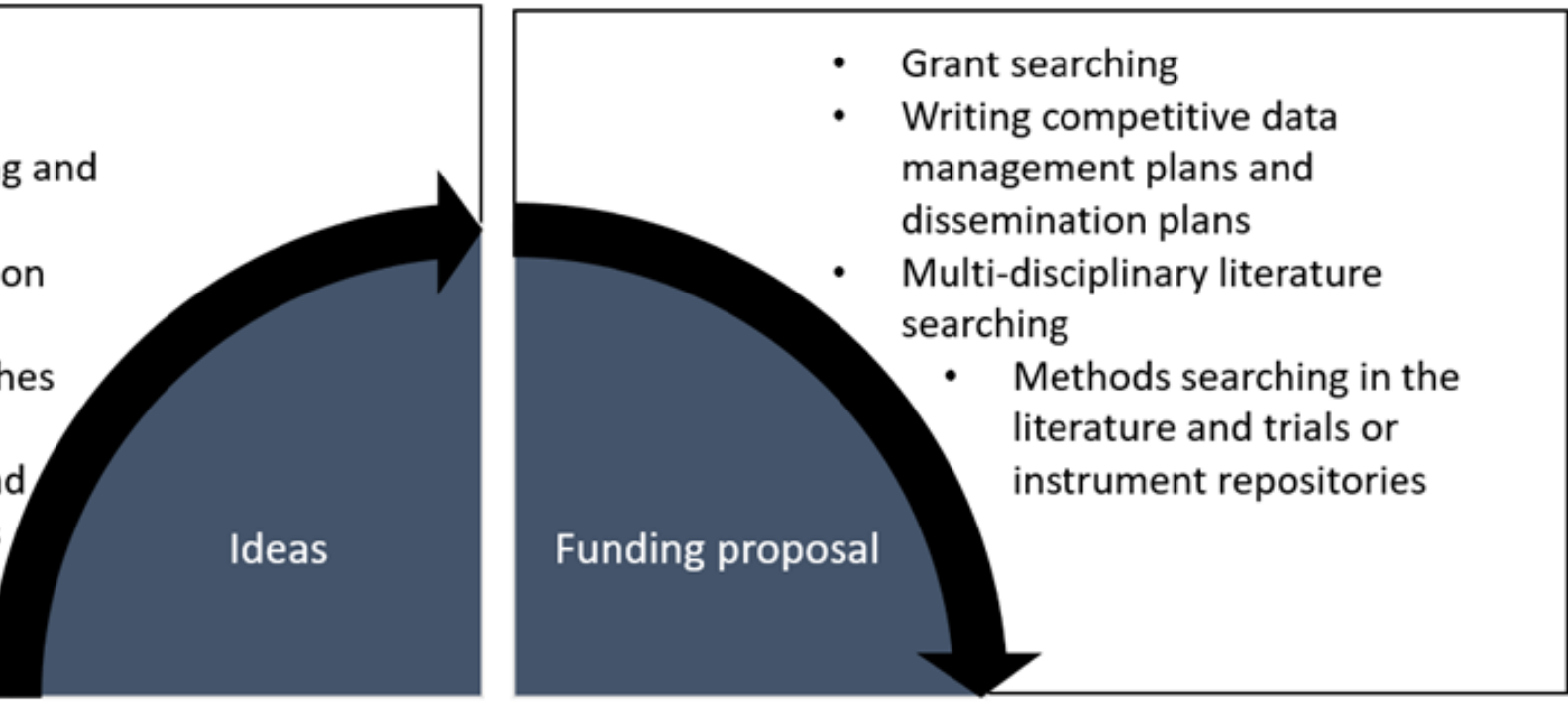

- Help identify data repositories

- Identify open access publication options, venues

- Identify journals and their rankings

- Citation management

- Advise on data sharing and preservation options

- Institutional repository

- Publishing services \& support

- Calculating research impacts

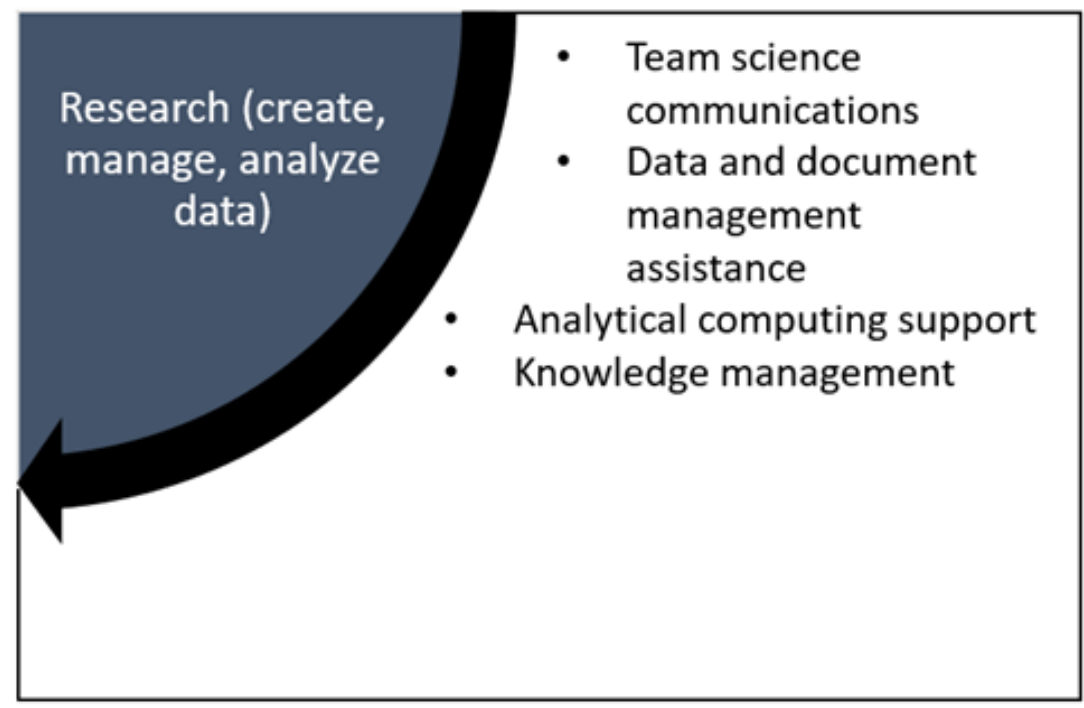




\section{Figure 3: Ways libraries and librarians can support research at their institutions}

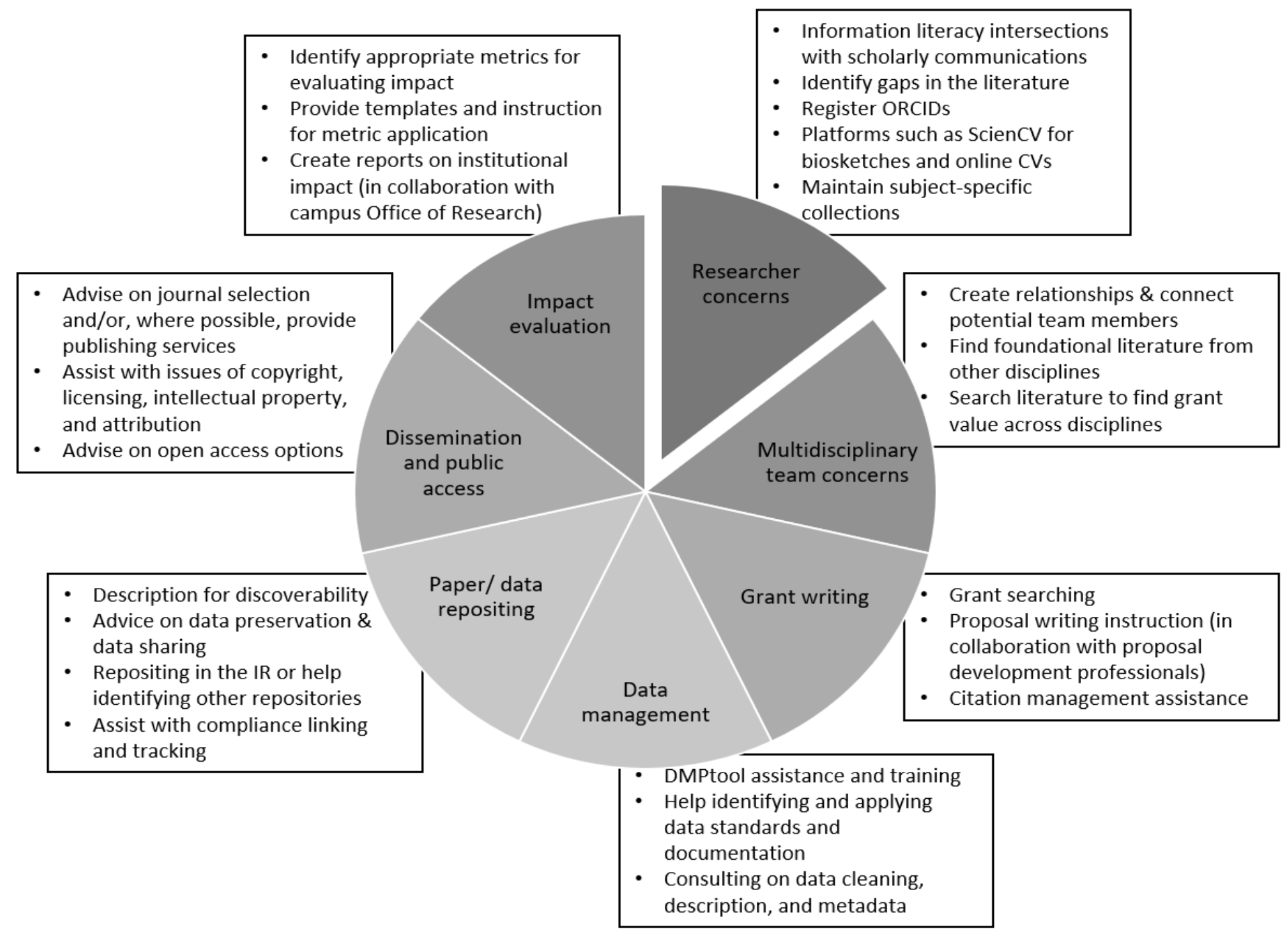

